\title{
EMI or TMI? \\ A Case Study on the Effect of English Medium Instruction on Prep-school Students' Success and Motivation
}

\author{
Ayse Yilmaz Virlan \\ Marmara University, Istanbul, Turkey
}

Dilara Demirbulak

Medipol University, Istanbul, Turkey

\begin{abstract}
English-medium instruction (EMI) has become a widely adopted approach, especially in higher education institutions not only in Europe but also in Turkey. Students may go for departments with 100\% English medium instruction as well as departments with $30 \%$ EMI, which are offered by many universities in Turkey. However, depending on the medium of instruction in their future departments, students may show different performance and attitude even when they are at prep schools. A quantitative case study was conducted to see if there is a relationship between the perceptions and the motivation as well as the success of EMI students at prep school. Attitude/Motivation Test Battery (AMTB) developed by Gardner in 1985 was utilized as the main data collection tool. The data includes responses of prep school students in a public university who were randomly chosen from the full EMI departments as well as 30\% EMI departments. Considering the success of the students, the results showed that there is a decrease in the achievement of the 100\% EMI students while there is an increase in the performance of $30 \%$ EMI students. Furthermore, no significant relationship was found between the test scores and the motivation level of the students. The study adds to our understanding of how different the students might perceive learning English for further academic instruction while they are receiving English courses at prep school lighting up the pathway for curriculum design studies of prep school programs.
\end{abstract}

\section{Suggested Citation:}

Yılmaz-Virlan, A., \& Demirbulak, D. (2020). EMI or TMI? A case study on the effect of English medium instruction on students' success and motivation. International Journal of Academic Research in Education, 6(1), 76-85. DOI: 10.17985/ijare.836119

${ }^{1}$ Dr, Marmara University, Istanbul, Turkey, ayseyilmazvirlan@gmail.com

${ }^{2}$ Assoc. Prof. Dr., Medipol University, Istanbul, Turkey, ddemirbulak@ hotmail.com 


\section{INTRODUCTION}

There is a striking tendency towards adopting English as the medium of instruction (EMI) for academic studies in many universities in non-English-speaking countries (Hue \& Lei, 2014). Several driving forces can be found behind the reason why adoption of EMI is preferred that much. To start with, Kirkpatrick (2014) claims that the Bologna Process is the most important motivation since it aims to standardize university degrees and allows staff and student mobility across Europe. As for Coleman (2006), financial concerns such as the marketization of university education play the biggest role in EMI adoption. Moreover, Dalton-Puffer (2011, p.185) suggests that "the perceived weakness of traditional foreign language teaching" makes it more important for universities to employ EMI in their degree programs. Finally, Hu and Lei (2014, p.552) consider EMI as an advantage to have "disciplinary learning and English proficiency" in higher education systems. Therefore, it is not surprising to observe an increase in the EMI programs at universities in the internationalization process the world is going through.

On the contrary, recent studies indicate that EMI instruction might negatively affect academic studies in higher education institutions. In one of their studies, Hu and Lei (2014) emphasize the fact that there are mixed or contradictory findings of EMI when the latest studies are examined. It is mostly observed in such research that students who were being forced to use a language different from their mother tongue had more problems than the students who could use their mother tongue in their academic studies. As to Hu \& Lei (2014) this, in turn, resulted in "a lower performance of the students on academic studies" owing to the difficulty students had while producing requested proficiency level in the target language. Additionally, UNESCO education policy also emphasizes the importance of first language usage that helps learning during instruction (Kirkpatrick, 2014). As it was also pointed out by Behan, et.al (1997), when the students did the appointed tasks using their native languages, the results showed higher quality when compared to the studies where students used a second language. For this very reason, when the role of the universities in that sense is reconsidered, it becomes crucially important to better understand the departmental courses through the language that is provided by the instructors. For this reason, the emphasis put on the medium of instruction that is examined by previous research emphasizes the significance of native-language instruction at the university level (Littlewood \& Yu, 2011; Benson, 2008; Kirkpatrick, 2014).

This being the case, it becomes even more necessary to find out what is considered attractive for students to choose an English-medium education in their academic studies (Kırkgöz, 2014). It is known that universities well-advertise themselves by offering a "British-style education" to appeal to the students (Kirkpatrick, 2014). Students are also offered prep school or support courses during their actual study. In short, EMI universities try to ensure that they provide their students with sufficient English education along with their degree courses (Kirkpatrick, 2014). Yet, when the students face with reality in their departments and prep schools of universities, things may differ.

One explanation made by Spolsky (2004) is that the language policy each student employs is a different mechanism. This mechanism consists of personal language practice and management with different beliefs and interactions during the implementation of the language within the course studies (Spolsky, 2004). Thus, what students perceive and perform in an EMI course might be quite different from what universities or program developers may foresee in their language policies. With these in mind, it is not difficult to encounter a lot of debate on whether academic studies should be conducted in the first language or following EMI policies. At this point, it becomes even more important to shed light on student perceptions of the second language in higher education. Hence, we first need to identify how students perceive EMI even when they start prep school to get a good command of English. 
Considering the factors affecting the choice of EMI, it seems that on the one hand, there are universities which try to accredit themselves with the international schools to get a higher ranking in terms of their quality. In addition to universities, there are parents who are eager to provide their children with an education that will fulfill their career goals, mostly with an EMI education (Kirkpatrick, 2014). On the other hand, there are the students, who learn best in their first language and even produce better scores (Benson, 2008).

Not very different from the rest of the non-English speaking countries, Turkey also experiences such complexities after having launched the EMI in most of its universities. With the desire to cope with the internationalization of higher education, and "to operate with other countries to foster close relations" (Demirel, 1990), universities in Turkey have started to employ EMI in their degree programs. For example, in the university that this study will take place, there are departments such as medicine and engineering, which offer English-only classes in their degree programs. On the other hand, there are also some departments such as jewelry design, which offer EMI only in a few of their courses. The rest of the courses in these departments are lectured only in the Turkish Medium of Instruction (TMI). English prep school is provided to all students at such universities if they cannot pass the proficiency test of the university. It does not matter how many of their degree courses are in English or Turkish; the students have to reach a proficiency level to follow the courses in English. In other words, because even one academic course with EMI requires a high level of competency in English, students are obliged to prove that their language level is sufficient to ensure successful study regardless of their discipline.

Under such circumstances, it is crucial to understand the students' perceptions of the EMI in their academic studies. Nevertheless, limited number of research has been conducted about what the students might think of English and what factors shape their attitudes towards it when they start prep schools (Kırkgöz, 2005). Hergüner (1990), Ciğdem (1994), Kırkgöz (2005) are some of the studies on the field, reporting students' problems when they receive EMI at universities (Kırkgöz, 2005). In addition to their studies, Sert (2008) investigated the effectiveness of EMI concerning instructor perceptions as well as student perceptions. It was reported that although EMI at the university level was effective as a part of language skill development, it was unsuccessful in conveying academic content in an efficient way (Sert, 2008). In another study, Collins (2010), reports that students feel disadvantaged during their university years, as they perceived their language proficiency as very low. To enhance student performance, then, it should be a must to provide students "a middle ground" in the departments that offer EMI (Collins, 2010).

Seen in this light, this research aims to fill the gap in identifying the perceptions of prep school students of EMI before they start their degree programs. It is aimed to see if the amount of English in the department courses plays an important role in students' decision about selecting their department at university. Besides, the study also tries to investigate if the English medium of instruction affects students' attitude towards language learning motivation, thereby affecting their success at prep school.

\section{Purpose of the study}

This study grounds its basis on the fact that students of full EMI departments of a university in Istanbul keep their performance around the same average in prep school, while students of half EMI seem to have a lower average according to the proficiency tests. Although the instructions, objectives of the program, course books and materials are the same, students of the departments which offer most of the courses in Turkish seem to be less successful. Thus, it is necessary to investigate the student perception and motivation underlying the success of the prep school programs. In this research study, it was aimed to better understand whether or not the prep-school students show any different attitude and performance 
depending on the amount of English, namely, as 100\% EMI intensive or 30\% EMI intensive as the medium of instruction in their future departments. Likewise, it is also essential to investigate how students perceive EMI offered at their appointed departments at the faculty. In that way, any possible changes related to curriculum and/or instructional strategies could be identified as an outcome of the study.

\section{Research Hypothesis}

Since the objective of this case study is to identify how prep-school students perceive English medium instruction at the university level, the research hypotheses were suggested as follows: "There is a difference between the $100 \%$ and $30 \%$ EMI students' academic performances in terms of prep-school studies. There is a positive relationship between students' academic performance and motivation". Thus, research questions listed below were formulated accordingly as:

1. Is there a difference between $100 \%$ EMI and 30\% EMI students' performances?

2. Is there a relationship between the students' performance and motivation?

\section{METHOD}

\section{Research Sample}

The sample group of the study consisted of 39 participants who were students at the English Prep Department at the School of Foreign Languages of a public university in Istanbul. Subjects were selected through convenience sampling method from the B1 level students, which implies that these students could not pass the proficiency test but received the highest scores in the placement test among all the other students. In so doing, any failure in their performance would be observed clearly when compared to the students in the lower levels. The classes which had 60 students in total were randomly appointed by the administration to conduct the study. These classes consisted of students of both $100 \%$ EMI and $30 \%$ EMI students. Out of 60 students, 39 students participated in the research study. There were 21 students from the $100 \% \mathrm{EMI}$ departments, and 18 students from the 30\% EMI departments participating in the study. The participants were aged between 18 and 21. They were students of different departments such as Dentistry, Engineering, Medicine as the 100\% EMI departments, and Jewelry Design, Public Relations, and Journalism as the 30\% EMI departments. However, the subjects were studying English in the preparatory program of the university during the study.

\section{Research Instrument and Procedure}

As the data collection tool, Gardner's Attitude/Motivation Test Battery (referred to as AMTB hereafter) developed in 1985 was utilized in this study. In the very beginning, the technical report of the AMTB was downloaded from http://publish.uwo. ca/ gardner/docs/AMTBmanual.pdf) to be further examined and adapted to this study. Out of 104 items in the test battery, 30 items were selected according to the main research focus. Items that were reported to have no effect on the reliability of the test were excluded for practical reasons. The categories related to attitude and motivation were used as the survey part of the questionnaire. The selected items of the test battery were also translated into Turkish to avoid any language-related problems.

The second data collection tool utilized was a placement test administered as an achievement test of the current research. The test had been developed by the testing office of the School of Foreign Languages and its reliability and validity were ensured by the test office before administration and conducted by the instructors of the prep-school immediately after the academic year started in September. Students had been already ranked depending on the results of this test, and placed into relevant B1 level classes when the study started. In December, the placement test was permitted to be used as the achievement test. 
The sections as well as the items of the test were shuffled to avoid any drawbacks that might stem from the memorization of the answers when used as the achievement test. Added to these, any possible extraneous variables such as instructors, materials and method of instruction were eliminated by applying the same procedures as of the placement test administration.

The placement test was used as the achievement test of this study to be able to investigate any changes in the academic performance of the students when pre-post test results are compared. After the students sat for the test, they were distributed the attitude and motivation questionnaire during their normal class sessions. All students were asked for their consent and acknowledged the process before the study was started for ethical considerations

\section{Data analysis}

To analyze the academic performance of the students, results that were obtained from the achievement test were compared through paired sample t-test analysis. The scores received from the tests were compared with the results obtained from the questionnaire through correlation analysis. It was aimed to find out whether or not there is a statistically significant relationship between the academic performances of the participants and their motivation with regards to EMI.

\section{FINDINGS}

\section{Performance}

To analyze any differences in the performance score of the subjects a paired sample t-test was computed. In that sense, the first table (Table 1) presents the mean differences of the achievement test scores of $100 \% \mathrm{EMI}$ and 30\% EMI students. The difference in the performance of $100 \% \mathrm{EMI}$ students in pre and post-tests is named "gain_100" and the difference in the performance of 30\% EMI students in these tests is named "gain_30" in the table.

Table 1: Mean Differences of Paired Samples

\begin{tabular}{lllll}
\hline & & $N$ & Mean & Std. Deviation \\
\hline \multirow{2}{*}{ Pair 1 } & gain_100 & 39 & $-2,12$ & 4,64 \\
& gain_30 & 39 & 10,35 & 4,38 \\
\hline
\end{tabular}

According to the findings, the gain score of $100 \% \mathrm{EMI}$ students is $M=-2.12, \mathrm{SD}=4.64$. This means that the performance of $100 \% \mathrm{EMI}$ students decreased as the mean is in the negative direction. As for the $30 \%$ EMI students, it is observed that the mean difference is $M=10.35, S D=4.38$, which means that there was a considerable increase in the performance of the 30\% EMI students. However, to understand if the differences between the groups are statistically significant, a paired sample t-test was conducted as can be seen in Table 2 . 
Table 2: Results of Paired samples t-test

\begin{tabular}{lllllll}
\hline & & Mean difference & Std. Deviation & $\mathrm{t}$ & $\mathrm{df}$ & $\mathrm{p}$ \\
\hline \multirow{2}{*}{ Pair 1 } & gain_100 & $-12,47$ & 6,53 & $-7,87$ & 16 & 0.000 \\
& gain_30 & & & & & \\
\hline
\end{tabular}

According to the figures in Table 2, there was a significant difference in the scores for the $100 \%$ students $(M=-2.12, S D=4.64)$ and $30 \%$ students $(M=10.35, S D=4.38)$ according to the pre and post-test results ( $t$ $(16)=-7.87, p=0.000)$. These results show that 30\% EMI students gained more than $100 \% \mathrm{EMI}$ students during the course. That is, $100 \%$ EMI students did not learn much probably because the materials were easy for them and they knew it before taking the course.

\section{Motivation}

A correlational analysis was computed to figure out any significant relationship between the success and the motivation of the $100 \%$ and 30\% EMI students. The results shown in Table 3 revealed that there is no significant correlation between the achievement of the 100\% EMI students and their motivation level $(r 19)=-.041, p=.0, p<.0)$. Besides, the correlation is negative, which means that the students' motivation was low while their scores in the pre-test were high. When we look at the relationship between the posttest scores of the $100 \%$ EMI students and their motivation, again we do not see a significant correlation $(r 19)=.031, p=.0, p<.0)$. However, this time the correlation is a positive one which means that the students' achievement also decreased while their motivation also decreased. The correlation matrix also reveals that there is a negative correlation which is not significant between pre-post test scores of participants $(r(19)=-.084$. This means that there is a decrease in the achievement of the students as the pre-test scores were higher while the post-test scores were lower as shown in Table 3. Obviously, $100 \%$ EMI students were not motivated as expected while they were receiving instruction in the prep school.

Table 3: Results of Correlations for the 100\% English department

\begin{tabular}{llll}
\hline & Pre_test & Post_test & Motivation100 \\
\hline Pre_test & 1 & & \\
Post_test & $-0,084$ & 1 & 1 \\
Motivation100 & $-0,041$ & 0,031 & 1 \\
\hline
\end{tabular}

A second correlational analysis was administered to investigate the relationship between achievement and motivation of 30\% EMI students. According to the figures in Table 4, the correlation between the pre and post-test scores of these students and their motivation is not statistically significant $(r(16)=-, 213)$. This might mean that 30\% EMI students were not motivated at all when they were to start prep school. However, although the correlation between the post-test scores and motivation is not significant, either $(r(16)=.148)$, the direction of the correlation changes from negative to positive when the students took the achievement test. As can be seen, the motivation of these students increased after they started learning English in prep school. Finally, the correlation between the pre and post-test is not a significant one $(r(16)=.027)$. The direction of the correlation shows that both the pre-post test results of the students increased. 
Table 4: Results of Correlations for the 30\% English department

\begin{tabular}{llll}
\hline & Pre_test & Post_test & Motivation30 \\
\hline Pre_test & 1 & & \\
Post_test & 0,027 & 1 & \\
Motivation30 & $-0,213$ & 0,148 & 1 \\
\hline
\end{tabular}

In short, the results indicate that neither the performance nor the achievement scores of the students of $100 \%$ EMI departments change in a positive direction. On the other hand, the results of students of $30 \%$ EMI departments increase not only in terms of motivation but also in terms of achievement. In other words, the only positive change could be observed in the results of students who would be studying in departments with $30 \%$ English instruction.

\section{DISCUSSION \& CONCLUSION}

One of the aims of the study was to find out if there was a difference between the 100\% EMI and 30\% EMI students' achievement. The study also tried to identify if there is a relationship between the students' achievement and motivation regarding their departments.

When we look at the results, we fail the reject our first hypothesis which was about the difference between the students' performances. As the results imply, we can observe a decrease in the achievement of $100 \% \mathrm{EMI}$ department students while there is an increase in the performance of students who are from 30\% EMI departments. In parallel with this study, it was suggested by Hue and Lei (2014) that there could be some contradictory results in the EMI studies which reveal that students may respond differently to English medium instruction. In our study, too, students in both groups receive the same instructions; nevertheless, their performance is not the same. Hue and Lei (2014) explains this as "the force to use a language which is not the mother tongue of the students which leads to a lower performance of the students" (Hue and Lei, 2014). One explanation of the results obtained in the study could be that students who would be studying at 100\% EMI departments after prep school might have felt under pressure resulting in their lower performance. Added to that, Collins (2010) also reports in his study that students may feel disadvantaged when they are exposed to a lot of foreign language instruction in their academic studies at the university level. This might also explain why students of $30 \%$ EMI departments had an upturn in terms of motivation after receiving instruction at the prep school.

Another analysis was conducted to test the second hypothesis of the study which tried to investigate whether there was a relationship between the students' performance and motivation. The students of 100\% EMI department obviously showed lower performance in the achievement test. Thus, in the second step of the study, an adaptation of Gardner's attitude and motivation test battery (developed in 1985) was utilized in order to examine the factors which might lead to lower performance. According to the results, however, there was no statistically significant relationship between the test scores and motivation levels of the students who would be imposed on a different amount of English instruction at their departments. Under such conditions we had to reject our second hypothesis about any possible relationship between the students' performance and achievement. 


\section{Recommendations}

The results show that there is a decrease in the achievement of the $100 \% \mathrm{EMI}$ students while there is an increase in the achievement of 30\% EMI students which provides us with the overall academic performance of the students. So, the first hypothesis about the difference between $100 \%$ and $30 \% \mathrm{EMI}$ students' performances is rejected. Furthermore, no significant relationship was found considering the achievement test scores and motivation level of the participants. Nevertheless, the findings of the study also show that students of $30 \% \mathrm{EMI}$ departments have a higher motivation level when compared to the students of $100 \%$ EMI departments.

One of the implications of the study could be that not all the time can we expect an increase in the performance of the students when instruction is given in English, even though the students elect the EMI departments on their wish. Besides, students with higher scores in the placement test may show lower performance later while students with lower scores may perform better during the prep class instruction regardless of their choice of medium instruction. In other words, we cannot claim that students who prefer $100 \%$ EMI departments are more motivated to learn English in prep school than the students who prefer 30\% EMI departments. There could be different motives behind the differences in the academic performance of the students in the prep school, however, in the study, such factors were tried to be eliminated by applying the same procedures simultaneously for each class. Therefore, the only differences between these two groups of students were their department and the amount of EMI in their departments, and the passing grade of the proficiency exam in the prep school. Hence, motivation level and exam stress could be considered as the main factors however, as the findings of the study imply, motivation doesn't play an important role as in the case of these students.

As a result, it can be suggested to conduct another study to see if exam stress is an important factor that leads to lower performance of students with higher scores students and better performance of students with lower scores. Additionally, a follow-up study could be conducted to see if there is a difference in students' attitudes towards learning English after they finish their first year in their department. Another study can be conducted with the other levels of the students as well, to find out if having to receive $100 \%$ EMI in the degree programs creates stress or pressure on prep students. The researchers could further study if knowing in the prep school that there are less EMI courses in the degree programs (as 30\% EMI students) affects their learning and performance. Such studies would also allow administrators to prepare their curriculum including the factors that affect the motivation levels and related performance of the students, as well. Also, as suggested by Kirkpatrick (2014) faculty departments at universities could be offered professional guidance on "how to decide which language a course should be delivered in" in light of such study if they can employ action research as part of their implementation of the instructions. In addition, instructors at prep school could be acknowledged that it does not always necessarily mean that when the students select a 100\% EMI department they are highly motivated, or students of $30 \% \mathrm{EMI}$ departments are to be less motivated. For students, this may be the other way around. That is, a student might have preferred a 30\%EMI department and be quite motivated to learn the language at prep-school while another student might felt pressurized as he would be receiving all his undergraduate courses in a second language. For this reason, the instructors should not take it for granted that all the students who choose to study in a full-English program are so eager to learn English in the prep-school.

As a consequence, it is obvious from the study that the need for universities to take into account today's linguistic trends as well as realities and to re-evaluate their language policies should not be disregarded if academically high standards are to be sought for. 
Notes:

This research study was presented as an oral paper entitled "The Effect of English Medium Instruction on Students' Success and Motivation in English Prep School" in the $3^{\text {rd }}$ International Eurasian Educational Research Congress Muğla, Turkey, in June 2016.

\section{References}

Behan, L., Turnbull, M., \& Spek, J. (1997). The proficiency gap in late French immersion: Language use in collaborative tasks. Le Journal de l'immersion, 20, 41-44.

Benson, C. (2008). Summary overview. Mother tongue-based education in multilingual contexts. In C. Haddad (Ed.), Improving the quality of mother tongue-based literacy and learning: Case Studies from Asia, Africa and South America (pp. 2-11). Bangkok: UNESCO.

Çiğdem, A. (1994). Implications of Student Attitudes Towards the Program of English in Mersin School of Tourism and Hotel Management (Adana: Çukurova University, 1994) Unpublished MA thesis.

Coleman, J.A. (2006). English-medium Teaching in European Higher Education. Language Teaching, 39, 14.

Collins, A. B. (2010). English-Medium Higher Education: Dilemma and Problems. Eurasian Journal of Educational Research, 39, 97-110.

Dalton-Puffer, C. (2011). Content-and-Language Integrated Learning: From Practice to Principles? Annual Review of Applied Linguistics, 31, 182-204. doi:10.1017/S0267190511000092

Demirel, O. (1990). Yabancı Dil Öğretimi. Ankara: Usem Yayınları.

Gardner, R.C. (1985). Attitude/Motivation Test Battery AMTB, retrieved from http://publish.uwo.ca/ gardner/docs/englishamtb.pdf

Gardner, R.C. (1985). Social Psychology and Second Language Learning. The Role of Attitudes and Motivation (London, Ontario: Edward Arnold).

Gardner, R.C. (2004). Attitude/Motivation Test Battery AMTB, Manual, retrieved from http://publish.uwo.ca/ gardner/docs/AMTBmanual.pdf

Hergüner, G. (1990). An Evaluation of the Graduate Level Preparatory Course as a Needs Assessment for a New Syllabus Design for Basic Science (Adana: Çukurova University) Unpublished MA thesis.

Hu, G., Lei, J. (2014). English-medium Instruction in Chinese Higher Education: a case study, Journal of Higher Education, 67, 551-567.

Kırkgoz Y. (2005). Motivation and Student Perception of Studying in an English-medium University, Journal of Language and Linguistic Studies, Vol.1, No.1, April 2005.

Kırkgöz, Y. (2014). Students' Perceptions of English Language versus Turkish Language Used as the Medium of Instruction in Higher Education in Turkey. International Periodical for Languages, Literature and History of Turkish or Turkic, 9/12, 443-459 
Kirkpatrick, A. (2014). The Language(s) of HE: EMI and/or ELF and/or Multilingualism? The Asian Journal of Applied Linguistics, 1(1), 4-15.

Littlewood, W., \& Yu, B. (2011). First language and target language in the foreign language classroom. Journal of Language Teaching, 44(1), 64-77.

Sert, N. (2008). The Language of Instruction Dilemma in the Turkish Context, System 36, 156-171. Spolsky, B. (2004). Language Policy. Cambridge University Press, Cambridge. 